\section{SEA-LEVEL RISE}

\section{Sinking sea}

Geophys. Res. Lett. http://doi.org/ngx (2013)

A significant drop in global sea level, up to a maximum of $-7 \mathrm{~mm}$, occurred in 2011 . This decline was the greatest seen since satellite measurements began and it coincided with an exceptionally strong La Niña event - to which it has been attributed.

John Fasullo, of the National Center for Atmospheric Research, USA, and co-workers use observations - satellite and in situ - and reanalysis data to explore the physical reason for the large fall in sea level. They find water storage in Australia contributed substantially to the decrease, with South America contributing to a lesser degree.

Australia has unique surface hydrology, which limits surface runoff to rivers and oceans. The continent received anomalously high precipitation from late 2010 to late 2011 due to the influence of the atmospheric circulation (Southern Annular Mode) and variability in sea surface temperature (Indian Ocean Dipole) on La Niña. The increased precipitation and water storage were the cause of the decline, highlighting the role that natural cycles have in global mean sea-level changes.

\section{ENVIRONMENTAL ECONOMICS Living roofs}

Environ. Sci. Technol. http://doi.org/nq9 (2013)

Rapid urbanization leads to increasing greenhouse gas emissions from rising energy demand and greater health impacts caused by deterioration of air quality. Green roofs can alleviate those problems, but upfront costs and lack of information delay wider adoption.

Jeffrey Mullen of the University of Georgia, USA, and colleagues compared the costs of conventional roofing with those of vegetated roofs (in present value terms) across 138 buildings in Atlanta under different scenarios. Choosing the green option saves on installation and maintenance costs (net private benefit) for buildings' owners for small roofs, but such benefits shrink with increasing roof size and vary across scenarios. The community at large would generally save storm-water management, air-quality and emissions costs (net public benefits) with little variation across scenarios. They found that government subsidies can support green roof adoption, but are most cost-effective if offered only to owners with no monetary incentive to invest in the technology.

\section{DECISION-MAKING \\ Participatory planning Appl. Geog. 45, 22-28 (2013)}

Policymakers are increasingly planning at local and regional levels for future climate-related impacts. The importance of stakeholders' involvement in such decisionmaking processes is discussed, but more evidence is needed to persuade institutions to include stakeholders for robust decisions.

Kathleen Ernst and her colleague Micheline van Riemsdijk, both of the University of Tennessee, USA, investigated the role of stakeholders in the Climate Change Scenario Planning (CCSP) for Alaska - a three-year project designed to help National Park System (NPS) managers develop plausible climate change scenarios
Terrestrial ecosystems constitute a significant $\mathrm{CO}_{2}$ sink, removing about $25 \%$ of anthropogenic $\mathrm{CO}_{2}$ emitted to the atmosphere. This land sink is responsive to climatic conditions, creating the potential for feedback loops that could reinforce or counteract anthropogenic climate change. An understanding of how the land sink responds to climate variability and change is therefore crucial in estimating the degree of climate change that can be expected in the future.

Ana Bastos from the Universidade de Lisboa, Portugal, and co-workers investigated the influence of the El Niño/Southern Oscillation (ENSO) on net primary productivity (NPP) - a measure of carbon uptake by plants - using satellite data and historical records of the strength of the land carbon sink.

They find that ENSO explains more than $40 \%$ of global NPP variability, mainly owing to the response of southern hemisphere ecosystems - particularly in tropical and subtropical regions. Water availability, controlled by temperature and precipitation anomalies, seems to be the main mechanism through which ENSO drives the regional changes in NPP. for all NPS areas in the state. Through participant observation and semi-structured interviews at two CCSP workshops held in 2012, the researchers found that contribution of non-NPS stakeholders allowed institutional barriers to be overcome and facilitated the understanding of attitudes about climate change. In addition, they found that the geographical context influenced decision-making. They concluded that the CCSP participatory approach could serve as a model for future climate change planning in public land agencies.

ECOLOGICAL IMPACTS

\section{Biological invaders}

Glob. Change Biol. http://doi.org/hrc (2013)

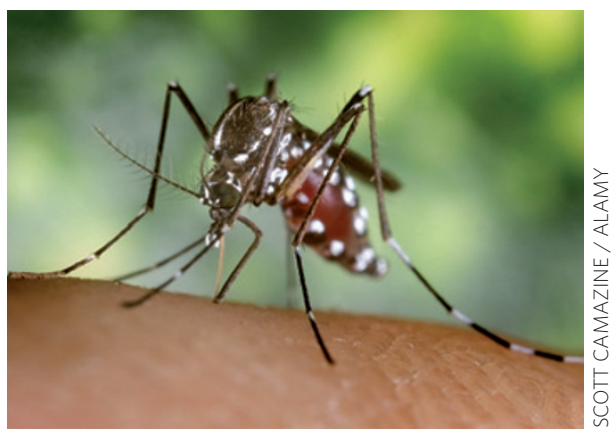

Biological invasion poses a serious threat to biodiversity. An important concern is how climatic changes might alter invasion dynamics and the extent to which this could enhance, or attenuate, the threat from invasive species. Céline Bellard from the Université Paris-Sud, France, and co-workers investigated this question using species distribution models to project changes in suitable areas for the world's 100 worst invasive species - as defined by the International Union for the Conservation of Nature.

Their results indicate that Europe, northeastern North America and Oceania are potential hotspots of invasion under climate and land-use change, with aquatic and terrestrial invertebrate distributions projected to substantially increase in most cases. However the news is not all bad; the authors also find a consistent shrinkage of suitable space for invasive species from certain groups, including amphibians and birds. Given the harmful impacts that invasive species have on ecosystems now, such changes are likely to have a significant influence on biodiversity in the future. $A B$ 